\title{
A mechanistic account of increasing seasonal variations in the rate of ocean uptake of anthropogenic carbon
}

\author{
T. Gorgues ${ }^{1}$, O. Aumont ${ }^{1}$, and K. B. Rodgers ${ }^{2}$ \\ ${ }^{1}$ LPO/IRD/CNRS (UMR 6523), centre IRD de Bretagne, Plouzané, France \\ ${ }^{2}$ Atmospheric and Ocean Sciences, Princeton University, Princeton, New Jersey, USA \\ Received: 9 January 2010 - Published in Biogeosciences Discuss.: 29 January 2010 \\ Revised: 15 July 2010 - Accepted: 19 July 2010 - Published: 31 August 2010
}

\begin{abstract}
A three-dimensional circulation model that includes a representation of anthropogenic carbon as a passive tracer is forced with climatological buoyancy and momentum fluxes. This simulation is then used to compute offline the anthropogenic $\Delta p \mathrm{CO}_{2}$ (defined as the difference between the atmospheric $\mathrm{CO}_{2}$ and its seawater partial pressure) trends over three decades between the years 1970 and 2000. It is shown that the mean increasing trends in $\triangle p \mathrm{CO}_{2}$ reflects an increase of the seasonal amplitude of $\Delta p \mathrm{CO}_{2}$. In particular, the ocean uptake of anthropogenic $\mathrm{CO}_{2}$ is decreasing (negative trends in $\Delta p \mathrm{CO}_{2}$ ) in boreal (austral) summer in the Northern (Southern) Hemisphere in the subtropical gyres between $20^{\circ} \mathrm{N}(\mathrm{S})$ and $40^{\circ} \mathrm{N}(\mathrm{S})$. In our simulation, the increased amplitude of the seasonal trends of the $\Delta p \mathrm{CO}_{2}$ is mainly explained by the seasonal sea surface temperature (SST) acting on the anthropogenic increase of the dissolved inorganic carbon (DIC). It is also shown that the seasonality of the anthropogenic DIC has very little effect on the decadal trends. Finally, an observing system for $p \mathrm{CO}_{2}$ that is biased towards summer measurements may be underestimating uptake of anthropogenic $\mathrm{CO}_{2}$ by about $0.6 \mathrm{PgC} \mathrm{yr}^{-1}$ globally over the period of the WOCE survey in the mid-1990s according to our simulations. This bias associated with summer measurements should be expected to grow larger in time and underscores the need for surface $\mathrm{CO}_{2}$ measurements that resolve the seasonal cycle throughout much of the extratropical oceans.
\end{abstract}

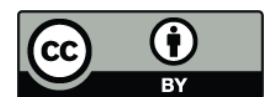

Correspondence to: T. Gorgues (thomas.gorgues@ifremer.fr)

\section{Introduction}

Currently anthropogenic activities (fossil fuel burning, deforestation and cement production) contribute approximately $7 \mathrm{PgC}$ of atmospheric $\mathrm{CO}_{2}$ each year (Marland et al., 2005; IPCC, 2007). Approximately half of this anthropogenic $\mathrm{CO}_{2}$ is absorbed by the ocean and the terrestrial biosphere (Battle et al., 2000; Sarmiento et al., 2000; Keeling and Garcia, 2002; Takahashi et al., 2002; Quay et al., 2003; Sabine et al., 2004). The ocean uptake response to the increased atmospheric partial pressure $\mathrm{CO}_{2}$ (hereafter $p \mathrm{CO}_{2 \mathrm{~atm}}$ ) has been the focus of a long series of publications (e.g., Sarmiento et al., 1992; Anderson et al., 2002; Takahashi et al., 2002, 2006, 2009; Corbiere et al., 2007; Rodgers et al., 2008; Ishii et al., 2009; Metzl et al., 2009). Most of them focus on the mean rates of change in the ocean uptake of atmospheric $\mathrm{CO}_{2}$ and use annual means for the partial pressure of $\mathrm{CO}_{2}$ in seawater (hereafter $p \mathrm{CO}_{2 \mathrm{sw}}$ ) or assume that its seasonal cycle remains unchanged (e.g. Takahashi et al., 2006, 2009; Schuster et al., 2009). But data-based studies in the North Atlantic have shown evidence for a decreasing flux of atmospheric $\mathrm{CO}_{2}$ into the sea surface, due to the faster-than-atmospheric rise of sea-surface $p \mathrm{CO}_{2}$ (e.g. Lefèvre et al., 2004; Corbiere et al., 2007; Omar and Olsen, 2006; Schuster and Watson, 2007; Le Quéré et al., 2009; Schuster et al., 2009; Watson et al., 2009). In these studies, hypotheses for the North Atlantic involving declining biological productivity (Lefèvre et al., 2004) or winter-time mixing and reduced buffer capacity (Schuster and Watson, 2007) have been offered to explain the seasonal decreasing $\triangle p \mathrm{CO}_{2}$ (here defined as the difference between $p \mathrm{CO}_{2 \text { atm }}$ and $\left.p \mathrm{CO}_{2 \mathrm{sw}}\right)$ trends. The modeling

Published by Copernicus Publications on behalf of the European Geosciences Union. 
study of Rodgers et al. (2008) identified seasonal changes in $\Delta p \mathrm{CO}_{2}$ as accounting for an important component of decadal changes in the North Pacific. However, as the reanalysis fluxes used to force the ocean model in that study included variations on all timescales (storms to decadal), it was not possible there to identify quantitatively specifically the seasonal effect. For that reason, we have chosen here an experimental design where the physical forcing consists of a repeating seasonal cycle over the period of the anthropogenic transient in atmospheric $\mathrm{CO}_{2}$ concentration. This allows for a focus specifically on the way in which the anthropogenic transient signal may project itself onto the seasonal cycle in ocean surface conditions.

The primary aim of this present work is to assess the different processes responsible for the decadal trends of the anthropogenic $\Delta p \mathrm{CO}_{2}$ over the global ocean. A parallel aim of this study is to test the hypothesis that an ocean observing network that does not resolve the seasonal cycle in surface ocean $p \mathrm{CO}_{2}$ will result in significant biases in the rate of uptake of $\mathrm{CO}_{2}$ by the ocean. After briefly presenting our method and describing the mean decadal trends in anthropogenic $\Delta p \mathrm{CO}_{2}$, our study will focus on the seasonality of these trends. Finally, the processes influencing these trends will be discussed.

\section{Method}

The model configuration considered here consists of a dynamical ocean-ice model, and a passive tracer module for the anthropogenic carbon perturbation that is run offline using output from the dynamical model. The dynamical component is the ORCA2-LIM global coupled ocean-ice model that is based on Version 9 of OPA (Océan PArallélisé). OPA is a finite difference model with a free surface and a nonlinear equation of state following the formulation of Jackett and McDougall (1995) (Madec and Imbard, 1996; Madec et al., 1998). The domain is global and extends from $78^{\circ} \mathrm{S}$ to $90^{\circ} \mathrm{N}$. The bottom topography and coastlines are derived from the study of Smith and Sandwell (1997), complemented by the ETOPO5 data set. Lateral mixing is oriented isopycnally, and the eddy parameterization scheme of Gent and McWilliams (1990) is applied poleward of $10^{\circ}$. Vertical mixing is achieved using the TKE scheme of Blanke and Delecluse (1993).

For the ORCA2 grid configuration, the zonal resolution is $2^{\circ}$, and meridional resolution ranges from $0.5^{\circ}$ at the equator to $2^{\circ}$ toward the poles. The model grid is tripolar, with two poles in the Northern Hemisphere (over North America and Siberia) and one centered over Antarctica. The model uses 31 layers in the vertical, with 20 of these layers lying in the upper $500 \mathrm{~m}$. The ocean model is coupled to a sea ice model (Fichefet and Maqueda, 1997; Goosse and Fichefet, 1999). The model was initialized with Boyer et al. (1998) and Antonov et al. (1998) salinity and temperature climatolo- gies. It was then spun up for 100 years with surface momentum forcing fields from a daily mean climatology of wind stress from the ERA40 reanalysis (Uppala et al., 2005).

In this study, only the anthropogenic perturbation of DIC $\left(\mathrm{DIC}_{\mathrm{ant}}\right)$ and $p \mathrm{CO}_{2 \mathrm{sw}}$ is computed offline using five-day mean circulation fields from the last year of the 100-year spin-up of a circulation model. This representation of the anthropogenic perturbation assumes that the natural (preanthropogenic) carbon cycle remained unchanged despite the anthropogenic increase (most importantly, biological fluxes remain stationary in a climatological sense). The anthropogenic air-sea $\mathrm{CO}_{2}$ fluxes are computed by taking the difference between the carbon fluxes which include the simulated perturbation and the natural carbon fluxes. The latter is inferred by reading monthly mean DIC and alkalinity surface fields as provided from a climatological experiment using PISCES as described in Aumont and Bopp (2006). The control simulation (hereafter DELC) has been forced by the atmospheric $\mathrm{CO}_{2}$ concentration from 1860 to 2000 (obtained from a spline fit to ice core and Mauna Loa observations, available at http://quercus.igpp.ucla.edu/ OceanInversion/inputs/atm_co2/splco2_mod.dat). The carbonate chemistry follows the OCMIP protocols (see the OCMIP website for more information at www.ipsl.jussieu.fr/ OCMIP) and the gas exchange coefficient is computed from the relationship of Wanninkhof (1992).

In order to identify the relative impacts of seasonal variations of DIC, SST, Alkalinity and Salinity on the $\Delta p \mathrm{CO}_{2}$ trends, we also performed a series of perturbate calculations using monthly and annual mean surface fields from the fully three-dimensional model. The anthropogenic partial pressure of carbon dioxide in the ocean's surface waters $\left(p \mathrm{CO}_{2 \mathrm{sw} \text {,ant }}\right)$ is determined by following the protocols of DOE (1994) from dissolved inorganic carbon (DIC), alkalinity, and the dissociation constants of carbonic acid. Using these perturbation calculations, we have decoupled the different processes responsible for the anthropogenic $\Delta p \mathrm{CO}_{2}$ trends in the global ocean.

\section{Results}

The annual mean linear trend in $\Delta p \mathrm{CO}_{2}$ over the period 1970-2000 reveals an increase over most of the global ocean (Fig. 1a), except for local signals along the Arctic coast of Russia and in Hudson Bay. Positive values indicate regions where the $p \mathrm{CO}_{2 \mathrm{sw}}$ lags the trend in the atmospheric $p \mathrm{CO}_{2}$ over 1970-2000. The annual mean pattern also reveals an extensive local minimum in the center of the subtropical gyres in both hemispheres (Fig. 1a) where the trend is almost zero. Local minima are also found in the eastern Bering Sea, the region east of Hokkaido and the region east of Newfoundland (Fig. 1a). In the annual mean, significant negative trends only occur along the Arctic coast of Russia and in Hudson Bay. The overall maximum is found along the Antarctic coast 

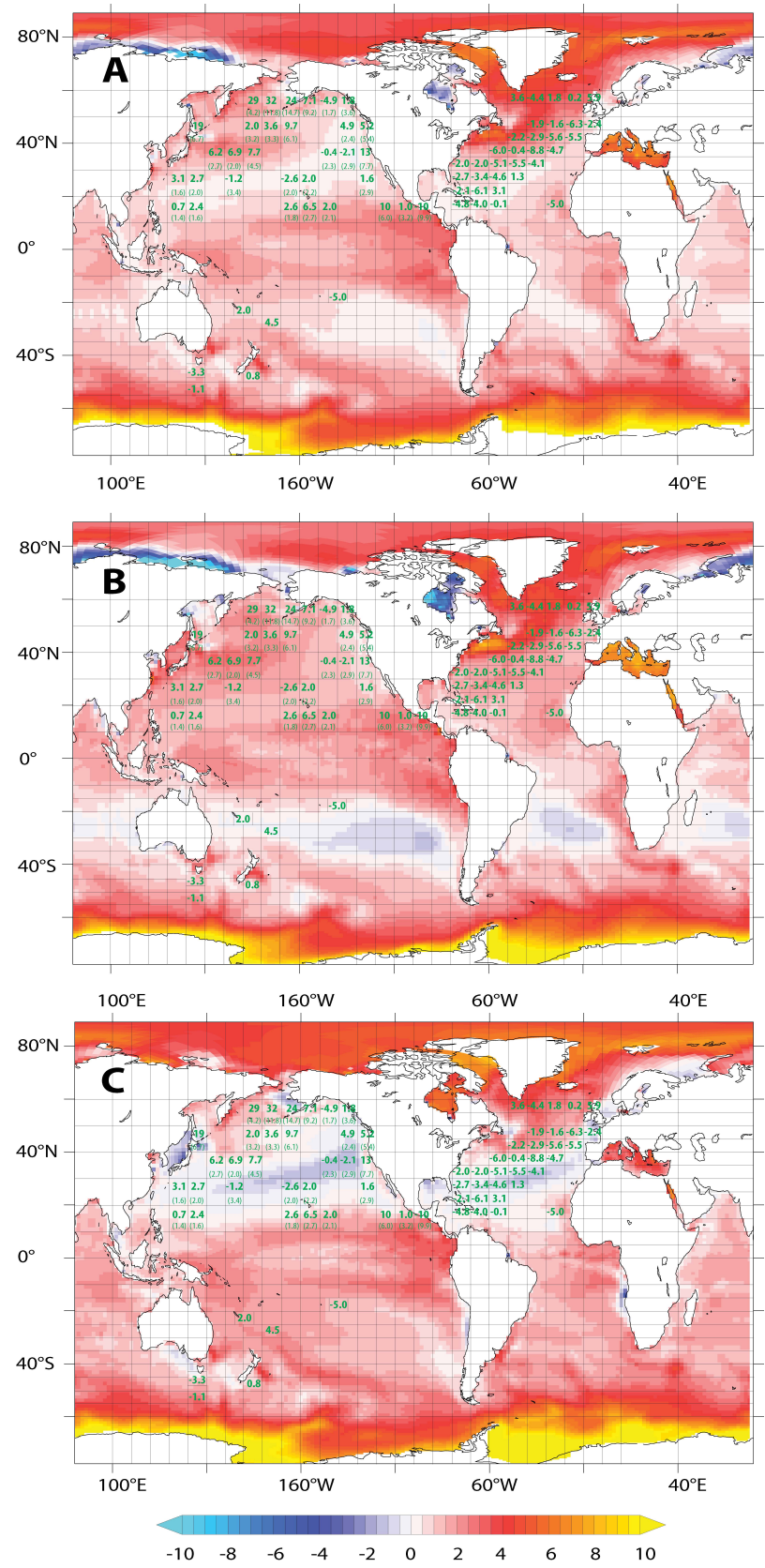

Fig. 1. (A) Decadal trends in the annual mean of $\Delta p \mathrm{CO}_{2}$ over 1970-2000 ( $\mu$ atm decade ${ }^{-1}$ ) computed from the annual mean of DIC, SST, Alkalinity and Salinity. (B) Decadal trends of $\Delta p \mathrm{CO}_{2}$ for February over 1970-2000 ( $\mu$ atm decade ${ }^{-1}$ ) computed from the DIC, SST, Alkalinity and Salinity in February. (C) same as B but for August (i.e. computed from the DIC, SST, Alkalinity and Salinity in August). The numbers in bold green letters indicate the decadal trends of $\Delta p \mathrm{CO}_{2}$ computed from Takahashi et al. (2006) and (2009) assuming a $1.5 \mu \mathrm{atm} \mathrm{yr}^{-1}$ increase of the atmospheric $\mathrm{CO}_{2}$ concentration over 1970-2000. The values in parenthesis indicate the uncertainty in the same unit. In boxes without parenthesis numbers, uncertainty ranges from 1 to $6 \mu$ atm decade ${ }^{-1}$. due to the ice sheet that shields the ocean from the anthropogenic increase of atmospheric $\mathrm{CO}_{2}$ and the emergence of water masses with low anthropogenic $p \mathrm{CO}_{2}$. Local maxima tend to be found along the equatorward and poleward margins of the subtropical gyres, in the polar seas, as well as in the Mediterannean. For the North Pacific, the structures here are consistent with the perturbation structures described in Rodgers et al. (2008). The annual mean as well as the February and August $\Delta p \mathrm{CO}_{2}$ trends presented here are also compared with the data analysis presented in the studies of Takahashi et al. (2006, 2009) (Fig. 1). For comparison, we have computed the $\Delta p \mathrm{CO}_{2}$ decadal trends from the $p \mathrm{CO}_{2 \mathrm{sw}}$ trends that were considered in those studies. Because the sampling of the data may be biased towards summer, the best agreement is found between the data-based $\Delta p \mathrm{CO}_{2}$ trends and the model trends for February (Fig. 1b). It has to be noticed that the data-based $\Delta p \mathrm{CO}_{2}$ trends are not directly comparable to our control simulation. Indeed, there are by construction no decadal changes in the physical or biological state of the ocean for our control simulation over the timeperiod considered in this study. Despite those limitations, the modeled trends are very often in the range of the trends computed from the data published in Takahashi et al. (2006, 2009) when uncertainty is taken into account as well as the sampling bias. It also appears that the trends published in Takahashi et al. (2006 and 2009) show local minima in the center of the subtropical gyres in the Northern Hemisphere, with this also being consistent with our control simulation.

Our main point in this study is to focus on mechanistic understanding through a series of sensitivity studies as a first step towards a more involved interpretation of data. The details of the degree of match or mismatch between the model and the observations should be left as a subject for further investigation, where we will consider a detailed Observing System Simulation Experiment (OSSE).

Figure $1 \mathrm{~b}$ and $\mathrm{c}$ shows the respective decadal trends of sea surface $\Delta p \mathrm{CO}_{2}$ for February and August considered separately over 1970-2000. In February, the Northern Hemisphere displays the same overall pattern (Fig. 1b) seen in the annual mean trend (Fig. 1a), with less pronounced minima in the subtropical gyres. Additionally, the negative decadal trend that was found near the Arctic coast of Russia and in Hudson Bay for the annual mean analysis is more pronounced in February. In the Southern Hemisphere, the subtropical local minima in February are more pronounced than in the annual mean case.

In August, the Northern Hemisphere summer displays negative $\Delta p \mathrm{CO}_{2}$ trends in the subtropical gyres for both the Pacific and Atlantic basins (Fig. 1c). The minima in the $\Delta p \mathrm{CO}_{2}$ trends east of Hokkaido and Newfoundland become slightly negative as well as for the eastern Bering Sea and the Japan Sea. On the other hand, the $\Delta p \mathrm{CO}_{2}$ trends associated with the anthropogenic transient increase in the Arctic coast of Russia and the Hudson Bay. In the Southern Hemisphere, the patterns are very similar to those already depicted for the 
annual mean (Fig. 1a) but with less pronounced minima in the subtropical gyre (Fig. 1c).

The decadal trend towards an increased mean annual uptake of anthropogenic $\mathrm{CO}_{2}$ over the period 1970-2000 (Fig. 1a) is then the result of a global increase of the anthropogenic $\Delta p \mathrm{CO}_{2}$ maximum in winter (boreal in the Northern Hemisphere and austral in the Southern Hemisphere) offsetting a slight decrease of the $\Delta p \mathrm{CO}_{2}$ in summer (boreal in the Northern Hemisphere and austral in the Southern Hemisphere) (Fig. 1b-c). Thus, the mean annual increased uptake of anthropogenic $\mathrm{CO}_{2}$ is in fact accompanied by an increase in the seasonal variability of the $\Delta p \mathrm{CO}_{2}$.

With this analysis of decadal $\Delta p \mathrm{CO}_{2}$ trends for winter and summer seasons considered separately for a repeating seasonal cycle in the physical state of the ocean, the most surprising aspect is that $p \mathrm{CO}_{2 \mathrm{sw}}$ in the subtropical gyres and in the Northern Hemisphere high latitudes tends to increase more rapidly than $p \mathrm{CO}_{2 \mathrm{~atm}}$. Why does this occur? In order to address the underlying mechanism, we performed a series of perturbation calculations. The partial pressure of anthropogenic $\mathrm{CO}_{2}$ at the ocean surface $\left(p \mathrm{CO}_{2 \mathrm{sw} \text {,ant }}\right)$ is computed using the monthly and annual mean output of modeled DIC, SST, sea surface salinity (SSS) and surface alkalinity using the method prescribed in DOE (1994). With all fields varying monthly, this perturbation method is able to reproduce well the evolution of $\Delta p \mathrm{CO}_{2}$ obtained with the control simulation (not shown).

In order to identify the relative impacts of seasonal variations in surface DIC concentrations, SST, alkalinity, and salinity on the decadal trends in the seasonal cycle of $\Delta p \mathrm{CO}_{2}$, a series of perturbation calculations were performed where one of these fields was maintained at its annual mean value while the others were allowed to vary seasonally. The resulting decadal $\Delta p \mathrm{CO}_{2}$ trends for February are shown in the first column of Fig. 2, and for August are shown in the second column. The case with annual mean alkalinity is henceforth referred to as MALK, the case with annual mean salinity as MSAL, the case with annual mean DIC as MDIC, and the case with annual mean SST as MSST.

We begin in Fig. 2 with a comparison of both the MALK (Fig. 2a-b) and MSAL (Fig. 2c-d) cases with our control simulation (Fig. 1b-c). In the Northern Hemisphere high latitudes (the Arctic coast of Russia and the Hudson Bay) the MALK case shows a greater amplitude of the seasonal cycles of the $\Delta p \mathrm{CO}_{2}$ trends. At lower latitudes, minima and maxima have a slightly greater amplitude in the MALK computation (Fig. 2a-b) than in MSAL (Fig. 2c-d) or the control simulation DELC (Fig. 1b-c). However, for both of these cases (MALK and MSAL), there is relatively little impact of holding the respective fields to their annual means on the decadal trend in $\Delta p \mathrm{CO}_{2}$ for February or August. This demonstrates that the trends in $\triangle p \mathrm{CO}_{2}$ are not to first order controlled by seasonal variations in either alkalinity or salinity except for the high latitudes in the Northern Hemisphere where alkalinity has a significant impact.
We next consider respectively the MDIC and MSST cases in Fig. 2e-f and Fig. 2g-h. For these cases, there are distinct differences in the $\Delta p \mathrm{CO}_{2}$ trends for both February and August when they are compared with the distributions seen in Fig. $1 \mathrm{~b}$ and c. At high latitudes (north of $70^{\circ} \mathrm{N}$ and south of $50^{\circ} \mathrm{S}$ ), the MDIC case reveals a reversed seasonal cycle with higher trends in winter (boreal for the Northern Hemisphere and austral for the Southern Hemisphere). At lower latitudes, MDIC (Fig. 2e-f) displays higher $\Delta p \mathrm{CO}_{2}$ trends in boreal winter (summer) in the Northern (Southern) Hemisphere. Geographical structures of the trends are also significantly different, with for example no local maxima in the Kuroshio or the Gulf Stream region evident during boreal summer. However, the most striking difference at mid latitudes is an amplified $\Delta p \mathrm{CO}_{2}$ seasonal cycle relative to what is seen in Fig. 1b-c. Negative trends in the North Pacific subtropical gyre reach $-4 \mu$ atm decade ${ }^{-1}$ (vs. $-2 \mu$ atm decade $^{-1}$ in DELC) when positive trends in boreal winter reach $5 \mu$ atm decade ${ }^{-1}$ (vs. $3 \mu$ atm decade ${ }^{-1}$ in DELC).

MSST (Fig. 2g-h) displays, at high latitudes (north of $70^{\circ} \mathrm{N}$ and south of $50^{\circ} \mathrm{S}$ ), a very similar to DELC (Fig. 1bc) seasonal cycle of the trends in $\triangle p \mathrm{CO}_{2}$. However at lower latitudes, MSST reveals more dramatic differences with the control simulation DELC. The seasonal cycle is reversed relative to DELC with Northern (Southern) Hemisphere lower trends in $\Delta p \mathrm{CO}_{2}$ occurring in February (August).

This indicates that: (i) the significant decadal trends in February and August $\Delta p \mathrm{CO}_{2}$ evident in Fig. 1 in the Northern Hemisphere high latitudes are mostly due to seasonal variations in DIC with the somewhat compensating effects of the alkalinity, (ii) at lower latitudes, the seasonal decadal trends are due to the compensating effects of the seasonal variation in SST and DIC. DIC variations, on one end, alkalinity and SST variations, on the other end, tend to act in opposite senses in their modulation of the decadal trends for the different seasons, such that the large impacts of each of these are partially compensating.

\section{Discussion}

The global-scale response of the decadal $\Delta p \mathrm{CO}_{2}$ trends for the surface ocean to the increased anthropogenic atmospheric $\mathrm{CO}_{2}$ varies geographically (Fig. 1) and also seasonally (Fig. 1b-c). A comparison of the control run (DELC) with the offline perturbation runs (MALK, MSAL, MDIC, and MSST) clearly demonstrated the first-order importance of the partially compensating effects of SST, alkalinity and DIC to controlling the seasonal trends in $\Delta p \mathrm{CO}_{2}$ seen in Fig. 1. In particular, the summertime trend in the subtropics for $p \mathrm{CO}_{2 \mathrm{SW}}$ to increase more rapidly than atmospheric $p \mathrm{CO}_{2}$ appears to be driven by seasonal variability in SST since it is opposed by seasonal variations in DIC concentrations and relatively unaffected by seasonality in alkalinity and salinity. Along the Arctic coast of Russia and in Hudson 

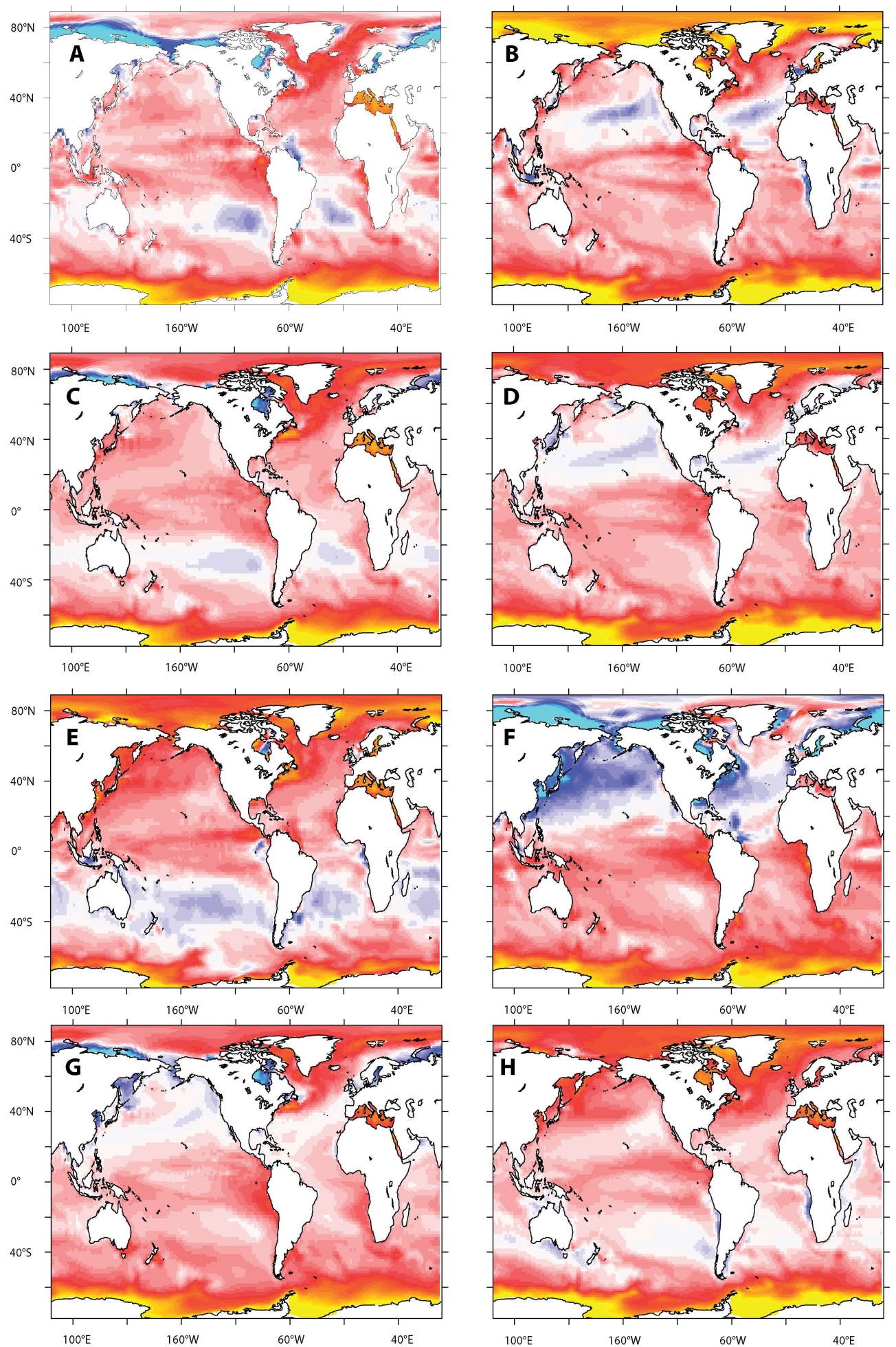

Fig. 2. (A) and (B) Decadal trends ( $\mu$ atm decade ${ }^{-1}$ ) in February (August) $\Delta p \mathrm{CO}_{2}$ over 1970-2000 computed from the annual mean of Alkalinity and the seasonal DIC, SST and Salinity; (C) and (D) same as (A) and (B) but using the annual mean of Salinity and the seasonal Alkalinity, DIC and SST in the $\Delta p \mathrm{CO}_{2}$ calculation; (E) and (F), same as (A) and (B) but using the annual mean of DIC and the seasonal Alkalinity, SST, and Salinity; (G) and (H) same as (A) and (B) but using the annual mean of SST and the seasonal DIC, Salinity, and Alkalinity. 

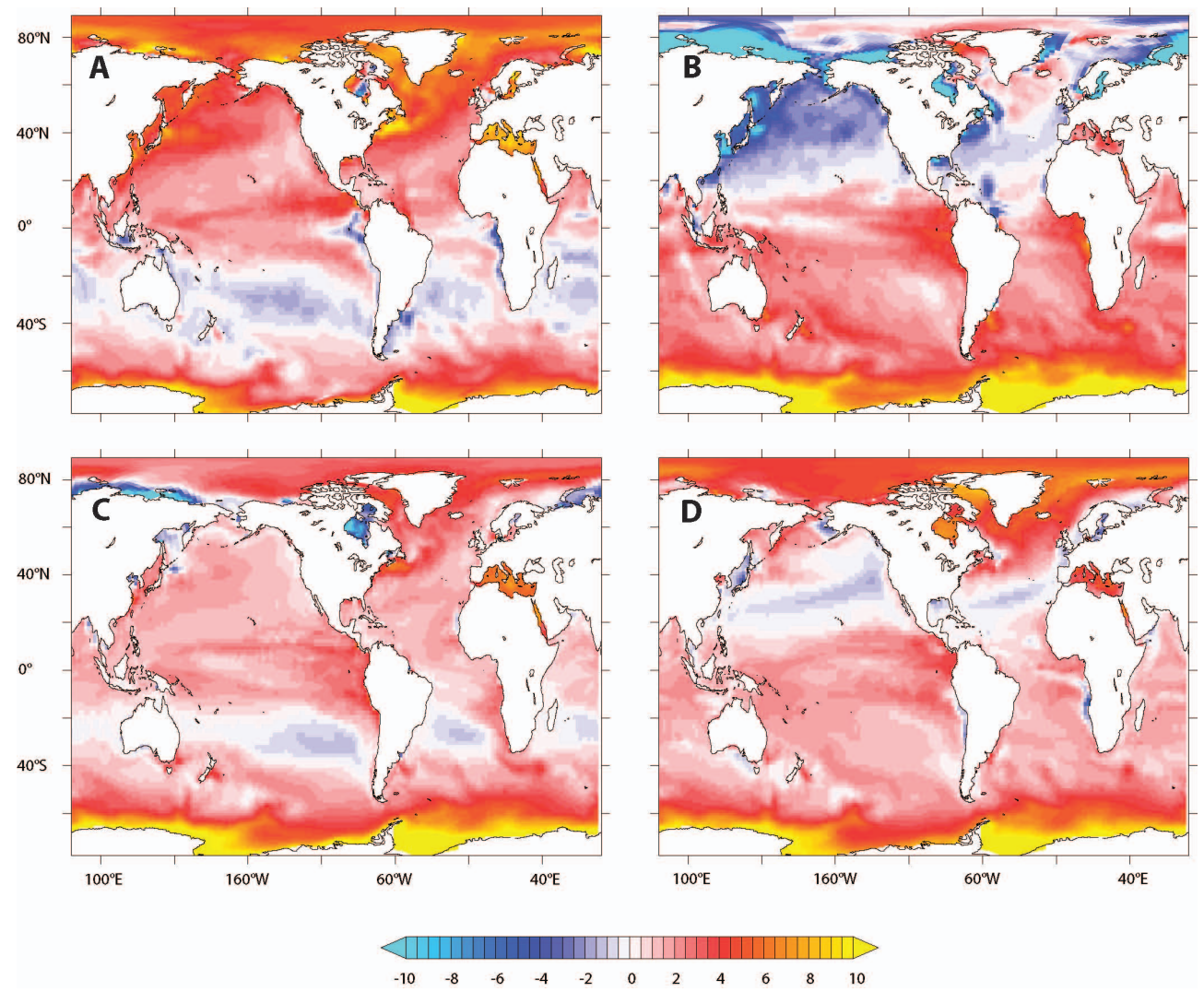

Fig. 3. (A) and (B) Decadal trends ( $\mu$ atm decade ${ }^{-1}$ ) in February (August) $\Delta p \mathrm{CO}_{2}$ over 1970-2000 computed from the annual mean of DIC $_{\text {pre }}$ and the seasonal SST, Alkalinity, Salinity and $\mathrm{DIC}_{\mathrm{ant}}$; (C) and (D), same as (A) and (B) but using the annual mean of the DIC $\mathrm{ant}_{\text {and }}$ the seasonal SST, Alkalinity, Salinity and DIC pre.

Bay, the seasonal trends are mainly driven by the seasonality of DIC counteracting the seasonality of alkalinity with little effects of the seasonality in salinity and SST.

However, in our simulation and perturbation calculations, by construction there are no decadal trends in surface temperatures or surface alkalinity. The climatological simulation imposed a repeating seasonal cycle in SST and in alkalinity for DELC and the perturbation computations. Thus in the subtropics, seasonal variations in SST alone cannot account for the amplified seasonality in $\triangle p \mathrm{CO}_{2}$ over 1970 2000. Unlike SST, DIC increases between 1970 and 2000 because of the increase in the $\mathrm{CO}_{2 \mathrm{~atm}}$ uptake (Fig. 1a). As noted in the results section, the MDIC case shows a significantly stronger increase of the seasonal cycle than the DELC simulation (Fig. 1b-c and Fig. 2e-f). In summer, the increase of DIC and the warm SST induce a year to year increase of $p \mathrm{CO}_{2 \mathrm{sw}}$ which happen to be faster than the increase of $\mathrm{CO}_{2 \mathrm{~atm}}$. The DIC increase has less impact in winter, because SST is colder and the mixed layer deepens bringing waters with low anthropogenic DIC to the surface. The seasonal trends of the anthropogenic $\Delta p \mathrm{CO}_{2}$ in DELC are then the result of the seasonal cycle of SST acting on an increasing DIC concentration.
In the Northern Hemisphere High Latitudes, the seasonal variation of the pre-anthropogenic DIC is higher than in most places because the high runoff that peaks in June and decreases the DIC along the Russian coast. The addition of the anthropogenic perturbation of DIC to the seasonal maximum of $\mathrm{DIC}_{\text {pre }}$ induces a year to year increase of $p \mathrm{CO}_{2 \mathrm{sw}}$ in boreal winter which happens to be faster than the increase of $\mathrm{CO}_{2 \mathrm{~atm}}$.

However, at this stage, the perturbation calculation presented in Fig. 2 does not allow one to distinguish between whether the SST or alkalinity are acting on a mean increase of the DIC seasonal cycle or on a modulation of the seasonal cycle in DIC.

An additional two perturbation calculations have then been performed in order to consider separately the deseasonalized trend in $\mathrm{DIC}_{\mathrm{ant}}$ and the seasonal component of the evolving $\mathrm{DIC}_{\text {ant }}$ distribution. This is presented in Fig. 3. For the first case here the pre-anthropogenic component of DIC $\left(\mathrm{DIC}_{\mathrm{pre}}\right)$ was maintained at annual mean values, and the seasonal component of $\mathrm{DIC}_{\mathrm{ant}}$ was superposed on this (Fig. 3a for February and Fig. 3b for August). For the second case the full seasonal cycle in $\mathrm{DIC}_{\text {pre }}$ was maintained and the deseasonalized trend in $\mathrm{DIC}_{\mathrm{ant}}$ was superposed (Fig. $3 \mathrm{c}$ for 

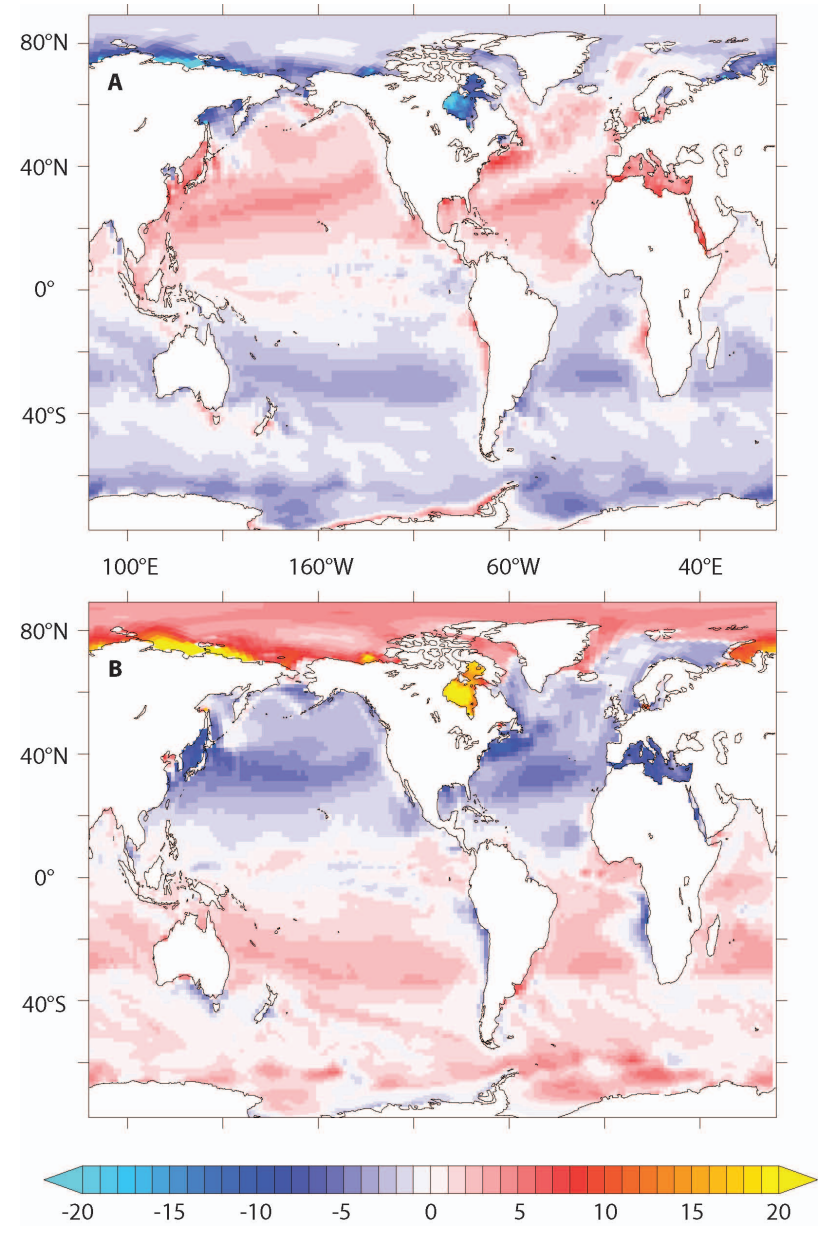

Fig. 4. (A) Difference ( $\mu \mathrm{atm})$ in 2000 between the mean anthropogenic $\Delta p \mathrm{CO}_{2}$ and the $\Delta p \mathrm{CO}_{2}$ computed from the boreal winter (February) trends only. (B) same as A but using the $\Delta p \mathrm{CO}_{2}$ computed from the boreal summer (August) trends instead of the winter trends.

February and Fig. 3d for August). Clearly the first of these two cases (Fig. 3a and b) most closely resemble the MDIC case (Fig. 2e-f). Using the annual mean of the full DIC (preindustrial and anthropogenic as in Fig. 2e-f) and using the annual mean of $\mathrm{DIC}_{\text {pre }}$ with the seasonal $\mathrm{DIC}_{\text {ant }}$ does not make any differences (Fig. 3a-b). Figure $3 \mathrm{c}$ and d looks very similar to DELC (Fig. 1b-c). This clearly demonstrates that it is the deseasonalized trend in $\mathrm{DIC}_{\text {ant }}$ that is acting in conjunction with seasonal variations in SST to drive the amplification of the seasonal cycle in $\Delta p \mathrm{CO}_{2}$ over 1970-2000.

The results considered here have potentially important implications for detection of anthropogenic perturbations in the carbon cycle. Recent studies have suggested that the rate of ocean carbon uptake may be slowing over the North Atlantic as there is a negative trend in $\Delta p \mathrm{CO}_{2}$ (Lefèvre et al., 2004; Corbiere et al., 2007; Omar and Olsen, 2006; Schuster and Watson, 2007; Le Quéré et al., 2009; Schuster et al., 2009). This type of behavior has been attributed to perturba-

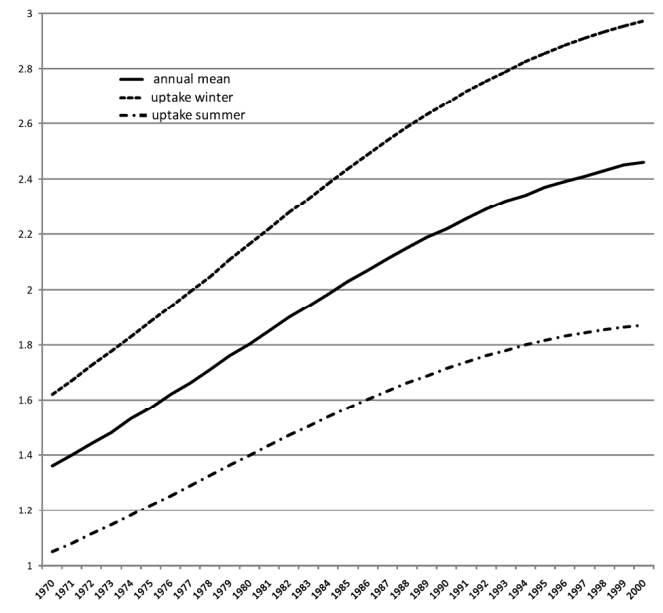

Fig. 5. Integrated anthropogenic global $\mathrm{CO}_{2}$ uptake (in $\mathrm{PgC} \mathrm{yr}^{-1}$ ) for annual mean fluxes (plain line), winter fluxes (dashed line), and summer fluxes (dashed dotted line). Summer (Winter) uptake is computed using the August (February) output north of $20^{\circ} \mathrm{N}$, the February (August) output south of $20^{\circ} \mathrm{S}$ and the annual mean outputs between $20^{\circ} \mathrm{N}$ and $20^{\circ} \mathrm{S}$.

tions in the physical climate system, and for the case of the North Atlantic to changes in the state of the Northern Annular Mode. However, we have seen in the control run (where there is no interannual or decadal variability) that sampling that is biased towards summer conditions could result in the inference of a negative trend in $\Delta p \mathrm{CO}_{2}$, even though this trend does not occur in the annual mean. Figure 4 does show that after 30 years of our simulation, the $\Delta p \mathrm{CO}_{2}$ computed from the boreal winter (summer) trends can differ in the subtropical gyres by almost $10 \mu \mathrm{atm}$. The seasonal bias in anthropogenic carbon uptake it represents is shown in Fig. 5. The global anthropogenic carbon uptake, relying on summer measurements of fluxes alone, would underestimate the rate at which anthropogenic carbon is entering the ocean (also seen in Table 1). Figure 5 and Table 1 both indicate that a bias towards summer measurements may lead to underestimate the ocean uptake of carbon by about $0.6 \mathrm{PgC} \mathrm{yr}^{-1}$ when both hemispheres are considered together during the WOCE decade of the 1990s. Thus although the results here are not intended to provide an interpretation of specific observations, they are intended as a cautionary note regarding the potential importance of aliasing problems with estimates that are reliant on summer data.

\section{Conclusions}

While the trends of the annual mean values are positive, the modeled seasonal cycle in the uptake of anthropogenic $\mathrm{CO}_{2}$ by the ocean increase in time in the absence of any interannual or decadal variations in the physical or biological state of the ocean. Uptake during winter tends to increase more 
Table 1. Carbon uptake (in $\mathrm{PgC} \mathrm{yr}^{-1}$ ) in 1970 and 2000 for summer, winter and the annual mean. The global carbon uptake for summer (winter) is calculated using the August (February) output north of $20^{\circ} \mathrm{N}$, the February (August) output south of $20^{\circ} \mathrm{S}$ and the annual mean outputs between $20^{\circ} \mathrm{N}$ and $20^{\circ} \mathrm{S}$.

\begin{tabular}{|c|c|c|c|c|c|c|c|c|c|}
\hline & \multicolumn{3}{|c|}{ Summer } & \multicolumn{3}{|c|}{ Winter } & \multicolumn{3}{|c|}{ Annual Mean } \\
\hline & 1970 & $\begin{array}{l}\text { Uptake } \\
\text { increase }\end{array}$ & 2000 & 1970 & $\begin{array}{l}\text { Uptake } \\
\text { increase }\end{array}$ & 2000 & 1970 & $\begin{array}{l}\text { Uptake } \\
\text { increase }\end{array}$ & 2000 \\
\hline $90^{\circ} \mathrm{S}-20^{\circ} \mathrm{S}$ & 0.62 & 0.48 & 1.10 & 0.85 & 0.72 & 1.57 & 0.75 & 0.61 & 1.36 \\
\hline $20^{\circ} \mathrm{N}-90^{\circ} \mathrm{N}$ & 0.10 & 0.07 & 0.17 & 0.44 & 0.37 & 0.81 & 0.28 & 0.22 & 0.50 \\
\hline $20^{\circ} \mathrm{S}-20^{\circ} \mathrm{N}$ & & & & & & & 0.33 & 0.27 & 0.60 \\
\hline Global Uptake & 1.05 & 0.82 & 1.87 & 1.62 & 1.36 & 2.98 & 1.36 & 1.10 & 2.46 \\
\hline
\end{tabular}

rapidly than the rate of uptake during summer. This view is in agreement with the hypothesis of a change in the seasonal cycle of the ocean uptake as shown by the data published by Lefevre et al. (2004) and previous modeling work (Rodgers et al., 2008). In order to identify the mechanisms responsible, a set of sensitivity studies was conducted. This revealed that the dominant driver over large scales is the interplay between seasonal variations in SST and the deseasonalized component of the trend in sea surface $\mathrm{DIC}_{\text {ant }}$.

This result with a state-of-the-art model suggests that the effect should be sufficiently large to make a first-order contribution to decadal trends in real-ocean $\Delta p \mathrm{CO}_{2}$. This effect should then be taken into consideration when interpreting historical time series, as it should be assumed to be a first-order effect among a number of other influences.

This increase in the seasonal cycle is sufficiently large that an observing system that relies only on summer measurements would underestimate $\mathrm{CO}_{2}$ uptake by the ocean. Our model predicts that in the absence of interannual to decadal variability in circulation or ocean biology, a summer bias in sampling of the subtropical gyres will lead to an erroneous inference of a trend towards decreased uptake by the ocean by more than $0.6 \mathrm{PgC} \mathrm{yr}^{-1}$ through the $1990 \mathrm{~s}$. This large amplitude in a summer bias would suggest that observations over large scales need to capture seasonal variations in $p \mathrm{CO}_{\mathrm{sw}}^{2}$ over large scales in order to adequately represent the ocean uptake of carbon.

The results shown in this study are the first steps to develop a detailed Observing System Simulation Experiment (OSSE), which is left as a subject for further investigation. OSSEs will play a critical role in planning the eventual extension of the current observing system for sea surface $p \mathrm{CO}_{2}$.

Acknowledgements. The contribution of K. B. Rodgers came through awards NA17RJ2612 and NA08OAR4320752, which includes support through the NOAA Office of Climate Observations (OCO). The statements, findings, conclusions, and recommendations are those of the authors and do not necessarily reflect the views of the National Oceanic and Atmospheric Administration or the US Department of Commerce.

Edited by: C. Heinze

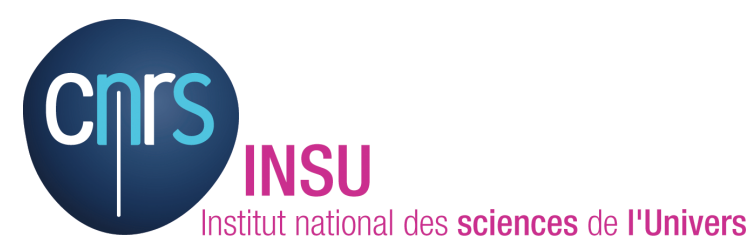

The publication of this article is financed by CNRS-INSU.

\section{References}

Anderson, L. G. and A. Olsen: Airsea flux of anthropogenic carbon dioxide in the North Atlantic, Geophys. Res. Lett. , 29(17), 1835 doi:10.1029/2002GL014820, 2002.

Antonov, J. I., Levitus, S., Boyer, T. P., Conkright, M. E., O’Brien, T. D., and Stephens, C.: World Ocean Atlas, 1998, Vol. 2: Temperature of the Pacific Ocean, NOAA Atlas NESDIS 28, 166 pp. 1998.

Aumont, O. and Bopp, L.: Globalizing results from ocean in situ iron fertilization studies, Global Biogeochem. Cy., 20, GB2017, doi:10.1029/2005GB002591, 2006.

Battle, M., Bender, M. L., Tans, P. P., White, J. W. C., Ellis, J. T., Conway, T., and Francey, R. J.: Global Carbon Sinks and their variability Inferred from Atmospheric $\mathrm{O} 2$ and $\delta 13 \mathrm{C}$, Science, 31 , 2467-2470, doi:10.1126/science.287.5462.2467, 2000.

Blanke, B. and Delecluse, P.: Variability of the tropical Atlantic ocean simulated by a general circulation model with two different mixed layer physics, J. Phys. Oceanogr., 23, 1363-1388, 1993.

Boyer, T. P., Levitus, S., Antonov, J., Conkright, M., O’Brien, T., and Stephens C.: World Ocean Atlas, 1998, Vol. 5, Salinity of the Pacific Ocean, NOA Atlas NESDIS 30, 166 pp., US Govt Print. Off., Washington, D.C., 1998.

Corbière, A., Metzl, N., Reverdin, G., Brunet, C., and Takahashi, T.: Interannual and decadal variability of the oceanic carbon sink in the North Atlantic subpolar gyre, Tellus B, 59, 2, 168-179, doi:10.1111/j.1600-0889.2006.00232.x, 2007.

DOE: Version 2 of "Handbook of Methods for the Analysis of the Various Parameters of the Carbon Dioxide System in Seawater", edited by: Dickson, A. G. and Goyet, C., ORNL/CDIAC-74, 1994. 
Fichefet, T. and Maqueda, M. M.: Sensitivity of a global sea ice model to the treatment of ice thermodynamics and dynamics, J. Geophys. Res., 102, 12609-12646, 1997.

Gent, P. R. and McWilliams, J. C.: Isopycnal mixing in ocean circulation models, J. Phys. Oceanogr., 20, 150-156, 1990.

Goosse, H. and Fichefet, T.: Importance of ice-ocean interactions for the global ocean circulation: a model study, J. Geophys. Res., 104, 23337-23355, 1999.

Ishii, M., Inoue, H. Y., Midorikawa, T., Saito, S., Tokieda, T., Sasano, D. Nakadate, A., Nemoto, K., Metzl, N., Wong, C. S., and Feely, R. A.: Spatial variability and decadal trend of the oceanic $\mathrm{CO}^{2}$ in the western equatorial Pacific warm/fresh water, Deep-Sea Res. II, 56, 591-606, doi:10.1016/j.dsr2.2009.01.002, 2009.

Jackett, D. R. and McDougall, T. J.: Minimal adjustment of hydrographic profiles to achieve static stability, J. Atmos. Oceanic Technol., 12, 381-389, 1995.

Keeling, R. F. and Garcia, H. E.: The change in oceanic O2 inventory associated with recent global warming, PNAS, 99, 78487853, doi:10.1073/pnas.122154899, 2002.

Lefèvre, N., Watson, A. J., Olsen, A., Rios, A. F., Pérez, F. F., and Johannessen, T.: A decrease in the sink for atmospheric $\mathrm{CO}^{2}$ in the North Atlantic, Geophys. Res. Lett., 31, L07306, doi:10.1029/2003GL018957, 2004.

Le Quéré, C., Raupach, M. R., Canadell, J. G., Marland, G., and Bopp, L., et al.: Trends in the sources and sinks of carbon dioxide, Nat. Geosci., 2, 831-836, doi:10.1038/NGEO689, 2009.

Madec, G. and Imbard, M.: A global ocean mesh to overcome the North Pole singularity, Clim. Dynam., 12, 381-388, 1996.

Madec, G., Delecluse, P., Imbard, M., and Levy, C.: OPA 8.1 General Circulation model reference manual, Notes du Pole de Modelisation de l'Institut Pierre-Simon Laplace, 11, 91 pp., http://www.lodyc.jussieu.fr/opa, 1998.

Marland, G. and Boden, T.: Global $\mathrm{CO}^{2}$ Emissions from Fossil-Fuel Burning, Cement Manufacture, and Gas Flaring: 1751-2002. Carbon Dioxide Information Analysis Center (CDIAC), Oak Ridge, Tennessee. http://cdiac.esd.ornl.gov/ftp/ ndp030/global.1751_2004.ems, 2005.

Metzl, N.: Decadal increase of oceanic carbon dioxide in the Southern Indian Ocean surface waters (1991-2007), Deep-Sea Res. II, 56, 607-619, doi:10.1016/j.dsr2.2008.12.007, 2009.

Quay, P., Sonnerup, R., Westby, T., Stutsman, J., and McNichol, A.: Changes in the $13 \mathrm{C} / 12 \mathrm{C}$ of dissolved inorganic carbon in the ocean as a tracer of anthropogenic $\mathrm{CO}^{2}$ uptake, Global Biogeochem. Cy., 17(1), 1004, doi:10.1029/2001GB001817, 2003.

Rodgers, K. B., Sarmiento, J. L., Aumont, O., Crevoisier, C., de Boyer Montégut, C., and Metzl, N.: A wintertime uptake window for anthropogenic $\mathrm{CO}^{2}$ in the North Pacific, Global Biogeochem. Cy., 22, GB2020, doi:10.1029/2006GB002920, 2008.
Sabine, C. L., Feely, R. A., Watanabe, Y. W., Lamb, M., et al.: The Ocean Sink for Anthropogenic $\mathrm{CO}^{2}$, Science, 305, 367-371, 2004. SABINE, C. L.,

Sarmiento, J. L., Orr, J. C., and Siegenthaler, U.: A Perturbation Simulation of $\mathrm{CO}^{2}$ Uptake in an Ocean General Circulation Model, J. Geophys. Res., 97, 3621-3645, 1992.

Sarmiento, J. L., Monfray, P., Maier-Reimer, E., Aumont, O., Murnane, R. J., and Orr, J. C.: Sea-air $\mathrm{CO}^{2}$ fluxes and carbon transport: a comparison of three ocean general circulation models, Global Biogeochem. Cy., 14, 1267-1281, 2000.

Schuster, U. and Watson, A. J.: A variable and decreasing sink for atmospheric $\mathrm{CO}^{2}$ in the North Atlantic, J. Geophys. Res., 112, C11006, doi:10.1029/2006JC003941, 2007.

Schuster, U., Watson, A. J., Bates, N. R., Corbiere, A., GonzalezDavila, M., Metzl, N., Pierrot, D., and Santana-Casiano, M.: Trends in North Atlantic sea-surface $f \mathrm{CO}^{2}$ from 1990 to 2006 , Deep-Sea Res. II, 56, 620-629, doi:10.1016/j.dsr2.2008.12.011, 2009.

Smith, W. H. F. and Sandwell, D. T.: Global seafloor topography from satellite altimetry and ship depth soundings, Science, 277, 1957-1962, 1997.

Takahashi, T., Sutherland, S. C., Sweeney, C., Poisson, A., Metzl, N. Tilbrook, B., Bates, N., Wanninkhof, R., Feely, R., Sabine, C., Olafsson, J., and Nojiri, Y.: Global sea-air $\mathrm{CO}^{2}$ flux based on climatological surface ocean $p \mathrm{CO}^{2}$, and seasonal biological and temperatude effects, Deep-Sea Res. Pt. II, 49, 1601-1622, 2002.

Takahashi, T., Sutherland, S. C., Feely, R. A., and Wanninkhof, R.: Decadal change of the surface water $p \mathrm{CO}^{2}$ in the North Pacific: a synthesis of 35 years of observations, J. Geophys. Res., 111, C07S05, doi:10.1029/2005JC003074.(2006),

Takahashi, T., Sutherland, S. C., Wanninkhof, R., Sweeney, C., Feely, R. A., Chipman, D. W., Hales, B., Friederich, G., Chavez, F., Sabine, C., Watson, A., Bakker, D. C. E., Schuster, U., Metzl, N., Yoshikawa-Inoue, H., Ishii, M., Midorikawa, T., Nojiri, Y., Körtzingerm, A., Steinhoffm, T., Hoppema, M., Olafsson, J., Arnarson, T. S., Tilbrook, B., Johannessen, T., Olsen, A., Bellerby, R., Wong, C. S., Delille, B., Bates, N. R., and de Baar, H. J. W.: Climatological mean and decadal change in surface ocean $p \mathrm{CO}^{2}$ and net sea-air flux over global oceans, Deep Sea Res. II, 56, 554-577, 2009.

Uppala, S. M., Kallberg, P. W., Simmons, A. J., Andrae, U., et al.: The ERA-40 re-analysis, Q. J. Roy. Meteor. Soc., 131, 29613012, 2005.

Wanninkhof, R.: Relationship between wind speed and gas exchange over the ocean, J. Geophys. Res., 97, 7373-7382, 1992.

Watson, A. J., Schuster, U., Bakker, D. C. E., Bates, N. R., et al.: Tracking the variable North Atlantic sink for atmospheric $\mathrm{CO}^{2}$, Science, 326, 1391, doi:10.1126/science.1177394, 2009. 